\title{
Organic Meat Production of Broiler Chickens Hubbard Redbro Cross
}

\author{
Yury Lysenko $^{1}$, Andrei Koshchayev ${ }^{1}$, Albina Luneva ${ }^{1}$, Ruslan Omarov ${ }^{2}$ and Sergei Shlykov ${ }^{2}$ \\ ${ }^{1}$ Kuban State Agrarian University named after I.T. Trubilin, Russia; ${ }^{2}$ Stavropol State Agrarian University, Russia \\ *Corresponding author: doooctor245@gmail.com
}

Article History: 20-126 Received: 27-May-20 Revised: 03-Jul-20 Accepted: 11-Jul-20
A BS TRA C T
This article presents the results of studying the impact of housing and feeding conditions on broiler chickens of
Hubbard RedBro cross, as well as the quality of products obtained when using floor and cage content, in a farm. It
established that when receiving a mixed feed of own production using feed raw materials grown on a farm without the
use of pesticides, a statistically significant decrease in potentially dangerous substances for animal health is recorded.
Compared with factory feed, it has reduced the content of pesticides by 14 times, and mercury and arsenic by 24
times, cadmium by five times, and lead by ten times. The results of the study of economic indicators of growing
Hubbard RedBro cross broiler chickens, as well as the chemical composition and quality of carcasses, indicated that
there was no significant difference between the floor and cell conditions of keeping. Still, the use of a diet based on
eco-feeds contributed to a statistically significant decrease in the concentration of toxic metals in the muscles of the
poultry of the experimental groups. As a result, it found that the use of the studied compound feed in the diets of
broiler chickens increased the indicators of Biosafety and ensured the production of environmentally safe ("organic")
poultry meat products.

Key words: Poultry, Organic meat, Eco-feed, Meat quality, Contaminants, Compound feed

(C2020 IJVS - All Rights Reserved

\section{INTRODUCTION}

The solution of an essential national economic problem of providing the population with food is directly related to the development of animal husbandry, in particular poultry farming. According to the program "development of poultry farming in the Russian Federation", the volume of poultry meat production in 2020 should be reached to 9.5 million tons. At the same time, the resulting poultry products must meet quality requirements and be environmentally safe food for the consumer (Luneva et al. 2019).

Due to the existence of an environmental problem in the world, today, it is relevant to conduct so-called "organic agriculture", which provides for improving the condition and productivity of the interdependent soils, plants, animals, and people (Yusfin et al, 2009; Lysenko et al. 2019; Nkosi et al. 2020). Organic agriculture based on minimizing the use of synthetic fertilizers and pesticides to obtain environmentally friendly products of crop and livestock production (Avarsky et al. 2014; Koshchaev 2018; Skvortsova et al. 2018; Boukili et al. 2020).

Thus, organic farming is essential, and the development of methods for growing environmentally friendly poultry products is a promising direction (Alagawany et al. 2019). The purpose of this research work is to study the impact of keeping and feeding conditions on the body of agricultural poultry of the Hubbard RedBro meat line, as well as the quality of the products obtained.

\section{MATERIALS AND METHODS}

Scientific and economic tests conducted in the farm "Khakonov MN" Republic of Adygea. The object of research was agricultural poultry of the Hubbard RedBro cross of the meat direction. To develop a method for producing "organic" poultry meat on a farm at a daily age, four groups of birds with 60 heads each formed using the technique of analogous groups. Two control and two experimental groups formed. Controls the first group, grown with floor content, the diet consisted of factoryproduced feed; the second group, grown with cellular material, the diet consisted of factory-produced feed. Breeding birds of the first group carried out outdoor. The diet consisted of eco-friendly grown products with the addition of $0.2 \%$ feed additives Batsell. Breeding birds of the second group carried out caging. The diet consisted of eco-friendly grown products with the addition of $0.2 \%$ Bazella.

In research work, poultry fed with compound feeds, the nutritional content of which corresponded to the norms.

Cite This Article as: Lysenko Y, Koshchayev A, Luneva A, Omarov R and Shlykov S, 2021. Organic meat production of broiler chickens Hubbard Redbro cross. International Journal of Veterinary Science 10(1): 25-30. https://doi.org/10.47278/journal.ijvs/2020.021 
Standard factory-made feed used for the control groups. For the experimental groups, we used the ecofood of our production, the components of which were grown on land without using any chemical treatment. The diet prepared using the feeding program "Feed Optima Expert". The biologically natural probiotic-enzyme feed additive Bacell used as an additional growth stimulator for poultry of experimental groups and an effective destructor of feed components. The duration of the scientific and economic experience corresponded to the period of economically feasible time for growing Hubbard RedBro cross poultry for meat production, as well as taking into account the physiological maturation of poultry products 84 days. A weekly study of the dynamics of the live weight of poultry in groups, using the method of individual weighing. The increase in live weight of birds in the scientific and economic experiment determined for the entire period of their maintenance. Daily monitoring of the safety and death of poultry carried out. Safety calculated as a percentage of the initial population for specific periods of poultry keeping and the entire period as a whole. Daily study of the consumption of compound feeds and feed additives by poultry was conducted. Based on the results obtained, feed costs per head and $1 \mathrm{~kg}$ of live weight gain calculated. The quality of poultry meat was assessed based on the results of a veterinary and sanitary examination of carcasses by the approved documentation. Determination of the $\mathrm{pH}$ value of poultry meat carried out on the $\mathrm{pH}$ meter, model I-500, according to GOST R 51478-99. According to GOST R 51944-2002 conducted a study of the organoleptic characteristics. The survey of microbiological contamination of poultry meat conducted by GOST R 50396.1-92. To analyze the digestibility of nutrients, as well as the coefficient of mineral use of compound feed, a balance experiment conducted in the last week of cross cultivation, according to the recommendations of All-Russian Research and Technological Institute of Poultry.

The analysis of the chemical composition of the muscle tissue of birds was carried out by the following methods sampling GOST 9792-73, determination of moisture content-GOST 9793-74, determination of fat content-GOST 23042-78, determination of protein content-GOST 25011-81. The amino acid score of poultry muscles was studied by capillary electrophoresis on the device "Kapel-103 RT", with preliminary hydrolysis of poultry protein by an acid method. The content of heavy metals (arsenic, lead, cadmium, and mercury) in factoryproduced and proprietary feed, as well as poultry muscle tissue, was performed by atomic absorption spectrometry using the electrothermal authorization of chemical elements. Determination of residual amounts of organochlorine pesticides in feed carried out by GOST 13496.20-2014 using thin-layer chromatography. The results obtained in the course of research experiments processed by the method of variational statistics. The difference was considered reliable at $\mathrm{P}<0.05$.

\section{RESULTS AND DISCUSSION}

\section{Study of the quality of feed}

After receiving eco-feeds, they studied for environmental safety indicators in comparison with factory-made feed (Table 1).
The results of the research showed that the level of potentially dangerous substances for the health of animals and birds in feed was below their maximum permissible concentration according to the requirements. At the same time, their content in the feed of their production was statistically significantly lower than in the feed of factory manufacture. Thus, the concentration of mercury and arsenic in eco-feed was lower than in factory feed by 24 times; cadmium was lower by five times; lead - by ten times and pesticides - by 14 times, with a statistically significant difference $(\mathrm{P}<0.05)$.

Thus, the use of proprietary components grown in the fields without chemical treatment contributed to the production of compound feed with higher Biosafety indicators.

\section{Study of zootechnical indicators of the Hubbard Redbro cross}

The results of the dynamics of growth, growth, feed consumption, and safety of poultry are present in Table 2 . The analysis of zootechnical indicators of the studied cross showed that the survival rate of birds in the experimental groups, regardless of the method of cultivation, was high and equivalent. The safety of poultry in the 1st experimental group was $95.0 \%$, which is more than in the $1 \mathrm{st}$ control group by $1.7 \%$. In the 2nd experimental group, the safety was $96.6 \%$, which is $1.6 \%$ higher than in the 2 nd control group. The difference in the studied indicator between experimental groups was insignificant and amounted to $1.6 \%$ in favor of the 2 nd group. In the first week of growth in weight of young animals in the 1st and 2nd control groups and amounted to 110.3 and $111.1 \mathrm{~g}$. and in the $1 \mathrm{st}$ and 2 nd experimental groups - 109.1 and 112.6g (Difference between experimental groups $-3.5 \mathrm{~g}$ ); in the second week in the $1 \mathrm{st}$ and 2nd control groups - 282.5 and RB $282.4 \mathrm{~g}$, and in the 1 st and 2nd experimental groups - 281.3 and $286.8 \mathrm{~g}$ (Difference $-5.5 \mathrm{~g}$ ); in the third week - and 540.3 and $541.7 \mathrm{~g}$. and 543.5 and 548.2g (Difference $-4.7 \mathrm{~g}$ ); in the fourth -862.7 and $861.8 \mathrm{~g}$ and 867.0 and $871.9 \mathrm{~g}$ (the difference $-4.9 \mathrm{~g})$; in the fifth -1202.4 and $1205.7 \mathrm{~g}$ and 1212.1 and 1218.1g (Difference - 6.0g); in the sixth 1573.2 and $1570.9 \mathrm{~g}$ and 1585.7 and 1586.2g (Difference $0.5 \mathrm{~g})$; in the seventh -1855.6 and $1857.8 \mathrm{~g}$ and 1873.9 and $1877.5 \mathrm{~g}$ (Difference $-3.6 \mathrm{~g}$ ); eighth -2171.3 and $2173.4 \mathrm{~g}$ and 2196.7 and $2198.2 \mathrm{~g}$ (Difference $-1.5 \mathrm{~g}$ ); ninth - 2464.7 and 2465.3g and 2482.4 and $2487.1 \mathrm{~g}$ (Difference $-4.7 \mathrm{~g}$ ); in tenth -2731.2 and $2732.8 \mathrm{~g}$ and 2753.3 and 2758.4g (Difference - 5.1g); in eleventh 2954.7 and 2957.1g and 2988.3 and 2992.3g (Difference $4.0 \mathrm{~g}$ ) and for the twelfth week of the live weight of birds made 3126.1 and $3127.8 \mathrm{~g}$ and 3171.5 and $3177.1 \mathrm{~g}$ (Difference - 5.6g). At the end of the experiment in experimental groups, there was a slight tendency of an increase in the live weight of birds compared to control. Which is the 1 st experimental group was higher than in 1 st control by $45.4 \mathrm{~g}$ or $1.4 \%$ and in 2 nd experimental group is more top than in the 2nd test and $49.3 \mathrm{~g}$ or $1.6 \%$.

In General, the increase in live weight of poultry over the entire period of its cultivation in the 1 st experimental group was $3131.9 \mathrm{~g}$ and in the second $-3136.8 \mathrm{~g}$, which is higher compared to similar groups from the control by 1.4 and $1.5 \%$. The increase in the second experimental group 
Int J Vet Sci, 2021, 10(1): 25-30.

Table 1: Quality of animal feed

Potentially dangerous substances, $\mathrm{mg} / \mathrm{kg}$

\begin{tabular}{cc} 
Compound feed & \\
\hline Own production (eco-feed) & Factory production \\
\hline $0.0004 \pm 0.00001^{*}$ & $0.0096 \pm 0.0001$ \\
$0.0061 \pm 0.0001^{*}$ & $0.1473 \pm 0.0015$ \\
$0.0114 \pm 0.0002^{*}$ & $0.0573 \pm 0.0017$ \\
$0.0303 \pm 0.0003^{*}$ & $0.3282 \pm 0.0016$ \\
$0.0003 \pm 0.00001^{*}$ & $0.0042 \pm 0.0001$
\end{tabular}

Mercury

Arsenic

Cadmium

Lead

Pesticides (DDT)

$0.0003 \pm 0.00001 *$

$0.0042 \pm 0.0001$

* - Difference with control is significant $(\mathrm{P}<0.05)$.

Table 2: Main economic indicators of Hubbard Redbro cross-country poultry, $n=60$

\begin{tabular}{|c|c|c|c|c|}
\hline \multirow[t]{2}{*}{ Indicator } & \multicolumn{4}{|c|}{ Group } \\
\hline & 1st control & 2nd control & 1st experienced & 2nd experienced \\
\hline Safety, $\%$ & 93.3 & 95.0 & 95.0 & 96.6 \\
\hline \multicolumn{5}{|l|}{ Live weight, $\mathrm{g}$} \\
\hline \multicolumn{5}{|l|}{ Growth period, weeks: } \\
\hline 1 & $110.3 \pm 1.9$ & $111.1 \pm 1.8$ & $109.1 \pm 2.3$ & $112.6 \pm 2.2$ \\
\hline 2 & $282.5 \pm 3.3$ & $282.4 \pm 3.3$ & $281.3 \pm 3.5$ & $286.8 \pm 3.6$ \\
\hline 3 & $540.3 \pm 5.6$ & $541.7 \pm 6.0$ & $543.5 \pm 6.3$ & $548.2 \pm 6.2$ \\
\hline 4 & $862.7 \pm 8.3$ & $861.8 \pm 8.5$ & $867.0 \pm 8.7$ & $871.9 \pm 8.6$ \\
\hline 5 & $1202.4 \pm 9.2$ & $1205.7 \pm 9.3$ & $1212.1 \pm 9.5$ & $1218.1 \pm 9.7$ \\
\hline 6 & $1573.2 \pm 11.3$ & $1570.9 \pm 11.1$ & $1585.7 \pm 10.5$ & $1586.2 \pm 10.3$ \\
\hline 7 & $1855.6 \pm 14.6$ & $1857.8 \pm 13.9$ & $1873.9 \pm 13.5$ & $1877.5 \pm 13.7$ \\
\hline 8 & $2171.3 \pm 19.4$ & $2173.4 \pm 18.2$ & $2196.7 \pm 18.7$ & $2198.2 \pm 18.5$ \\
\hline 9 & $2464.7 \pm 23.2$ & $2465.3 \pm 21.7$ & $2482.4 \pm 22.5$ & $2487.1 \pm 22.6$ \\
\hline 10 & $2731.2 \pm 27.3$ & $2732.8 \pm 26.9$ & $2753.3 \pm 26.7$ & $2758.4 \pm 26.5$ \\
\hline 11 & $2954.7 \pm 27.2$ & $2957.1 \pm 28.5$ & $2988.3 \pm 28.4$ & $2992.3 \pm 28.3$ \\
\hline 12 & $3126.1 \pm 31.1$ & $3127.8 \pm 30.8$ & $3171.5 \pm 30.3$ & $3177.1 \pm 30.5$ \\
\hline \multicolumn{5}{|c|}{ Body mass gain (1-84 days) } \\
\hline One head, g & $3087.9 \pm 29.6$ & $3088.3 \pm 30.3$ & $3131.9 \pm 30.7$ & $3136.8 \pm 30.5$ \\
\hline Daily average, $g$ & $36.8 \pm 0.2$ & $36.8 \pm 0.2$ & $37.3 \pm 0.3$ & $37.3 \pm 0.4$ \\
\hline \multicolumn{5}{|c|}{ Consumption of feeds (day 1-84) } \\
\hline Per 1 head, $g$ & 8875.2 & 8878.5 & 8867.8 & 8872.4 \\
\hline Per $1 \mathrm{~kg}$ of growth, $\mathrm{kg}$ & 2.87 & 2.87 & 2.83 & 2.82 \\
\hline
\end{tabular}

Table 3: Digestibility of feed nutrients by poultry, $\%$

\begin{tabular}{lcccc}
\hline Indicator & \multicolumn{3}{c}{ Group } \\
\cline { 2 - 5 } & 1st control & 2nd control & 1st experienced & 2nd experienced \\
\hline Dry matter & $60.1 \pm 0.6$ & $60.3 \pm 0.6$ & $62.3 \pm 0.7$ & $63.2 \pm 0.6$ \\
Organic matter & $55.2 \pm 0.5$ & $55.0 \pm 0.6$ & $57.8 \pm 0.7$ & $57.9 \pm 0.7$ \\
Crude protein & $84.4 \pm 0.8$ & $84.2 \pm 0.8$ & $86.1 \pm 0.9$ & $87.0 \pm 0.8$ \\
Crude fat & $70.6 \pm 0.6$ & $71.1 \pm 0.7$ & $72.3 \pm 0.8$ & $73.5 \pm 0.7$ \\
Crude fiber & $34.7 \pm 0.3$ & $35.0 \pm 0.3$ & $45.1 \pm 0.3 *$ & $45.3 \pm 0.4 *$ \\
NFES (nitrogen-free extractive substances) & $58.4 \pm 0.4$ & $59.1 \pm 0.5$ & $60.6 \pm 0.4$ & $61.5 \pm 0.3$ \\
\hline
\end{tabular}

* - Difference with the control is significant $(\mathrm{P}<0.05)$.

Table 4: Chemical composition of poultry meat

\begin{tabular}{lcccc}
\hline Indicator & \multicolumn{3}{c}{ Group } \\
\cline { 2 - 5 } & 1st control & 2nd control & 1st experienced & 2nd experienced \\
\hline Moisture, \% & $70.2 \pm 1.3$ & $69.8 \pm 1.3$ & $69.9 \pm 1.2$ & $70.4 \pm 1.3$ \\
Protein \% & $18.7 \pm 0.3$ & $18.4 \pm 0.3$ & $18.6 \pm 0.3$ & $18.9 \pm 0.2$ \\
Fat \% & $9.6 \pm 0.2$ & $10.4 \pm 0.3$ & $10.0 \pm 0.2$ & $9.3 \pm 0.2$ \\
Ash, \% & $1.5 \pm 0.03$ & $1.4 \pm 0.03$ & $1.5 \pm 0.02$ & $1.4 \pm 0.02$ \\
Index of meat quality & $1.9 \pm 0.03$ & $1.8 \pm 0.04$ & $1.9 \pm 0.03$ & $2.0 \pm 0.03$
\end{tabular}

was slightly higher than in the first by $0.2 \%$. When taking into account the average daily increase, it found that in the control groups, it was $36.8 \mathrm{~g}$, and in the experimental groups it was $37.3 \mathrm{~g}$, which is higher by $0.5 \mathrm{~g}$ or $1.3 \%$.

Analysis of feed consumption during the entire period of growing Hubbard RedBro cross showed that in the 1st control group $8875.2 \mathrm{~g}$ of compound feed per head, and in the 2nd control group $8878.5 \mathrm{~g}$, which is slightly higher than in the 1st and 2nd experimental groups, in which this indicator was 8867.8 and $8872.4 \mathrm{~g}$, respectively. In General, the conversion of feed in the 1 st experimental group was
$2.83 \mathrm{~kg}$, and in the $2 \mathrm{nd}-2.82 \mathrm{~kg}$, which is $1.4 \%$ lower than this indicator in the control groups of the same name.

Thus, the research results showed that the conditions of poultry rearing did not affect their zootechnical signs, but the use of feed additives in the diet had the best effect (Mottet and Tempio 2017).

\section{Study of digestibility of feed components and mineral balance}

The results of the digestibility and use of nutrients in feed presented in Table 3 . 
Int J Vet Sci, 2021, 10(1): 25-30.

Table 5: Heavy metal content in poultry meat, $\mathrm{mg} / \mathrm{kg}$

\begin{tabular}{|c|c|c|c|c|}
\hline \multirow{2}{*}{$\begin{array}{l}\text { Toxic } \\
\text { element }\end{array}$} & \multicolumn{4}{|c|}{ Group } \\
\hline & 1st control & 2nd control & 1st experienced & 2nd experienced \\
\hline \multicolumn{5}{|c|}{ Pectoral muscle } \\
\hline Arsenic & $0.0085547 \pm 0.0000532$ & $0.0083362 \pm 0.0000554$ & - & - \\
\hline Cadmium & $0.0042257 \pm 0.0000512$ & $0.0042101 \pm 0.0000522$ & $0.0013512 \pm 0.0000465 *$ & $0.0013487 \pm 0.0000459 *$ \\
\hline Mercury & $0.0003421 \pm 0.0000045$ & $0.0003367 \pm 0.0000062$ & - & - \\
\hline Lead & $0.0247331 \pm 0.0002635$ & $0.0247267 \pm 0.0002655$ & $0.00176436 \pm 0.0000648 *$ & $0.00176411 \pm 0.0000633 *$ \\
\hline \multicolumn{5}{|c|}{ Leg muscles } \\
\hline Arsenic & $0.0066432 \pm 0.0000487$ & $0.0066389 \pm 0.0000493$ & - & - \\
\hline Cadmium & $0.0035253 \pm 0.0000437$ & $0.0035168 \pm 0.0000454$ & - & - \\
\hline Mercury & $0.0003035 \pm 0.0000078$ & $0.0003064 \pm 0.0000069$ & - & - \\
\hline Lead & $0.0035317 \pm 0.0001749$ & $0.0035257 \pm 0.0001732$ & $0.00063637 \pm 0.0000184 *$ & $0.00063604 \pm 0.0000168 *$ \\
\hline
\end{tabular}

*-Difference with the control is significant $(\mathrm{P}<0.05)$.

Table 6: Physical, chemical and microbiological indicators of poultry meat quality.

\begin{tabular}{lcccc} 
Indicator & \multicolumn{3}{c}{ Group } \\
\cline { 2 - 5 } & 1st control & 2nd control & 1st experienced & 2nd experienced \\
\hline Reaction with copper sulfate & - & - & - & - \\
Reaction with formalin & - & - & - & - \\
Reaction to the peroxidase & + & + & + & + \\
Quantity of LDL, mg KOH/100g & $1.26 \pm 0.02$ & $1.31 \pm 0.02$ & $1.27 \pm 0.02$ & $1.30 \pm 0.02$ \\
Several microbial cells in one field of view of the microscope: & $3.34 \pm 0.09$ & $3.35 \pm 0.10$ & $3.33 \pm 0.10$ & $3.30 \pm 0.09$ \\
- from the surface of the carcass & - & - & - & - \\
- from deep layers & & & & \\
The pH of the meat, units & & & & $6.86 \pm 0.18$ \\
The first day & $6.86 \pm 0.17$ & $6.88 \pm 0.19$ & $6.83 \pm 0.20$ & $6.47 \pm 0.26$ \\
Second day & $6.43 \pm 0.24$ & $6.40 \pm 0.25$ & $6.45 \pm 0.21$ & $6.05 \pm 0.13$ \\
Third day & $6.09 \pm 0.16$ & $6.10 \pm 0.14$ & $6.07 \pm 0.15$ &
\end{tabular}

The results of the physiological experiment showed that the digestibility of raw fiber of compound feeds by Hubbard RedBro cross in the 1st and 2nd experimental groups had a statistically significant increase in comparison with the poultry of the control groups by 10.4 and $10.3 \% \quad(\mathrm{P}<0.05)$. For other analyzed indicators, a substantial difference in the context of studied groups and degree of nutrients digestibility for a bird of dry matter in the 1 st control group was $60.1 \%$ and in the 2 nd control of $60.3 \%$ and the 1 st experimental $-62.3 \%$ and in the 2nd - 63.2 percent (Difference between experimental groups was $-0.9 \%)$. For the organic matter in the 1 st control group $-55.2 \%$ and in the 2 nd - of $55.0 \%$. In the 1 st experimental - of $57.8 \%$ and the 2 nd $-57.9 \%$ (the difference $-0.1 \%$ ). For crude protein - for 84.4 and $84.2 \%$, and $87.0-86.1 \%$ (Difference $-0.9 \%$ ). For raw fat 70.6 and $71.1 \%$, and 72.3 and $73.5 \%$ (Difference $-1.2 \%$ ). Nitrogen-free extractives (NFES) - 58.4 and $59.1 \%$, and 60.6 and $61.5 \%$ (Difference $-0.9 \%$ ).

Analysis of the exchange of phosphorus and calcium in the body of poultry showed no significant difference between the experimental groups studied. The results of the experiment shows that the amount of calcium taken with feed in the 1 st control group was $0.48 \mathrm{~g}$, in the 2 nd control group $-0.46 \mathrm{~g}$, in the 1 st experimental group $0.46 \mathrm{~g}$, and in the 2 nd experimental group $-0.47 \mathrm{~g}$. When analyzing the samples of litter, the content of this indicator in the $1 \mathrm{st}$ control group was $0.33 \mathrm{~g}$, and in the remaining groups $0.31 \mathrm{~g}$. Considering the difference between obtained data revealed that in the body of the bird, 1st and 2nd control groups and 1st experienced postponed $0.15 \mathrm{~g}$ of calcium, and in $2 \mathrm{nd}-0.16 \mathrm{~g}$, which is $31.2,32.6,32.6$ and $34.0 \%$ of the total accepted feed. In General, the coefficient of calcium used in the experimental groups was higher than in the control groups by $1.4 \%$. A similar value of this indicator observed when the difference between experimental groups in favor of the second. When studying the phosphorus utilization coefficient, it found that in 1st and 2nd control groups, the difference between the consumed compound feed and the undigested element understudy was $0.12 \mathrm{~g}$. In the $1 \mathrm{st}$ and 2nd experimental groups, the difference was $0.13 \mathrm{~g}$. In General, the phosphorus utilization rate in the $1 \mathrm{st}$ experimental group was $30.9 \%$, and in the 2nd group$31.7 \%$, which is 0.9 and $2.4 \%$ higher compared to similar control groups. The difference between the experimental groups was 0.8\% (Erwan 2018; Piskaeva et al. 2017).

Thus, the use in feeding fodder of own production with the feed additive had a better effect on the digestibility of the components of the feed mixture and balance of minerals, regardless of cell or litter content.

\section{Assessment of the quality of poultry meat}

Table 4 shows that there is no statistically significant difference in the studied parameters in the context of experimental groups. The amount of moisture in poultry meat in the control groups was 70.2 and $69.8 \%$ and in the experimental groups-69.9 and 70.4\%. The difference between the experimental groups was $0.5 \%$. Protein content into birds' muscles, regardless of maintenance method and feeding, was almost equal and in control, groups were 18.7 and $18.4 \%$, and in the experimental groups -18.6 and $18.9 \%$, respectively. The amount of fat in the 1 st control group was $9.6 \%$. In the 2 nd control group $-10.4 \%$, in the 1 st experimental group $-10.0 \%$, and the 2 nd $-9.3 \%$. It should have been noting that the ratio of protein and fat (quality index) of meat characterizes its dietary indicators. Thus, the poultry meat quality index of 
the 1st experimental group was equal to this indicator in the 1 st control group and amounted to 1.9 units. However, in the 2nd experimental group, this indicator was higher than in the 2 nd control group by 0.2 units.

The nutritional properties of meat are determined not only by its chemical composition but also by signs of biological usefulness, which is characterized by essential amino acids of muscle protein. The amino acid composition of muscle protein assessed by the content of lysine, tryptophan, phenylalanine, leucine, and methionine in poultry meat of the studied groups was determined (Prosekov et al. 2015; Belloir et al. 2017; Miska and Fetterer 2019).

The results of studying the amino acid score of muscles showed that in the experimental groups, to the control groups, there was a tendency to a slight increase in the content of essential amino acids in poultry meat. This pattern not observed in the context of experimental groups. The amount of lysine in the 1st and 2nd experimental groups was higher than into control groups by 0.9 and $1.3 \%$. The level of tryptophan in the experimental groups was 27.8 and $27.9 \mathrm{mg} / \mathrm{g}$, which is 1.4 and $2.5 \%$ higher than in the control groups. The content of phenylalanine in poultry meat of experimental groups was 54.2 and $54.4 \mathrm{mg} / \mathrm{g}$, while in the $1 \mathrm{st}$ and 2 nd control groups -53.2 and $53.4 \mathrm{mg} / \mathrm{g}$, respectively. The difference between the indicators of phenylalanine was $1.8 \%$ in favor of the experimental groups. The level of leucine in the $1 \mathrm{st}$ and 2nd experimental groups was higher than in 1st and 2nd control groups by 2.7 and $3.6 \mathrm{mg} / \mathrm{l}$. A similar trend observed in the content of methionine in studied birds' meat, the level of which in the experimental groups was higher than in the control groups by 1.9 and $3.8 \%$.

To determine the taste qualities of poultry products, a tasting evaluation of cooked pectoral and leg muscles of the studied groups, as well as broth from them, was conducted the results of the tasting assessment in the context of groups were high, and no significant difference found. The broth obtained by cooking the muscles of all the studied groups was slightly straw-colored and had a pleasant taste and aroma characteristic of poultry meat. Large drops of fat found on the surface of the broth. The cooked meat obtained from all the experimental groups tasted pleasant, flavorful, tender, and moderately juicy. There were no foreign odors that could have been taking from the meat and broth obtained from the experimental groups (Hilliar et al. 2019; Chrystal et al. 2020).

Since the research aimed to get clean and safe poultry products, one of the leading indicators is the characteristics of the meat of birds at the studied concentration of heavy metals is also consistent with the decision of the commissioners of the food and agriculture organization of the United Nations and who. According to the food code, sanitary norms, and rules, all food products must pass quality control about the content of toxic elements. In this regard, poultry meat analyzed for arsenic, cadmium, mercury, and lead (Table 5).

According to SanPiN 2.3.2.1078-01, the limit of permissible concentration of heavy metals in meat products should not exceed the following values: for lead0.5 ; cadmium-0.05; mercury-0.03 and arsenic $0.1 \mathrm{mg} / \mathrm{kg}$.
The results of the research showed that the content of arsenic, cadmium, mercury, and lead in poultry meat of all groups was lower than the MPC. Table 5 shows that in the flesh of experimental groups of birds grown with floor and cell content, using eco-feeds, there was a statistically significant decrease in the studied indicators concerning the control groups. It should have been noting that when considering the content of certain toxic elements in the meat of experimental birds, their absence observed. Thus, in the pectoral muscles of birds of the experimental groups, there were no heavy metals such as arsenic and mercury, while in the 1 st control group, the value of these elements was 0.0085547 and $0.0003421 \mathrm{mg} / \mathrm{kg}$, and in the 2nd control group -0.0083362 and $0.0003367 \mathrm{mg} / \mathrm{kg}$. In the leg muscles of birds of the 1 st and 2 nd experimental groups, arsenic, cadmium, and mercury not detected, while in the 1st control group, the concentration of these toxic elements was $0.0066432 ; 0.0035253$ and $0.0003035 \mathrm{mg} / \mathrm{kg}$, and the 2nd control 0.0066389 ; 0.0035168 and $0.0003064 \mathrm{mg} / \mathrm{kg}$, respectively. The results of the analysis of bird's pectoral muscles by the concentration of cadmium showed that its level in the experimental groups was statistically significantly lower than in the control groups by 3.1 times $(\mathrm{P}<0.05)$. A similar trend observed in the content of lead in the pectoral muscles of birds of the experimental groups, the level of which was 14 times lower than in the control groups, with a statistically significant difference $(\mathrm{P}<0.05)$. A statistically significant difference also observed in the content of lead in the leg muscles, the concentration of which in the experimental groups was lower than in the control groups by 5.5 times $(\mathrm{P}<0.05)$.

Thus, using developed compound feed with Bacell into birds' diet helped to improve quality indicators of broiler chicken meat, regardless of the conditions of their maintenance.

\section{Veterinary and sanitary assessment of poultry meat}

It should have been noting that a Biosafety of meat is determined not only by the content of toxic elements in it but also by veterinary and sanitary expertise, which includes the study of several indicators of product quality (Lemme et al. 2019; Hofmann et al. 2019). The first stage of veterinary and sanitary examination is a pathoanatomic autopsy, the results of which indicated that there were no changes in the morphological structure of organs and tissues of birds. The location of the organs in the abdominal and pleural cavities was anatomically correct; the presence of fluid not recorded. There was a free lumen of the trachea and bronchi. The lungs were slightly pink. The mucous membrane of the gastrointestinal tract was free of hemorrhages, erosions, and ulcers. A day after the birds' slaughter, a "drying crust" observed onto the carcasses surface, which had a whitish-yellow color with a hint of pink. The consistency of the bird's muscles was elastic and dense, and the hole formed when pressed quickly returned to its original state. When the muscles cut, there was little humidity. In General, the presence of pathology not observed in the study of poultry carcasses of control and experimental groups. All the signs mentioned above characterized the meat as fresh and 
obtained from a healthy bird. The results of physicochemical and microbiological studies describing poultry meat freshness presented in Table 6 .

Table 6 shows that in all groups, poultry meat subjected to a reaction with copper sulfate gave a negative result, since the broth remained transparent after adding the compound, and there were no flakes or other formations. The response with formalin was also negative since the soup remained transparent and acquired a greenish-yellow color, which indicated the absence of ammonia and ammonium salts. When conducting a reaction to the presence of peroxidase, as one of the main factors of meat shelf life, it found that the extract obtained from the meat of experimental birds, acquired a blue-green color, turning into a brown-brown, which indicates its freshness and that obtained from a healthy bird. According to the approved documentation, the content of volatile fatty acids in poultry meat should be within the range of $4.5 \mathrm{mg}$ $\mathrm{KOH} / 100 \mathrm{~g}$, the values we obtained in control and experimental groups meet the requirements and amounted to $1.26 ; 1.31 ; 1.27$ and $1.30 \mathrm{mg} \mathrm{KOH} / 100 \mathrm{~g}$. When microscopy of smears-prints from the surface of bird carcasses, isolated cases of microflora, mainly cocci, were recorded, and from the deep layers of muscles, the results of the research showed the absence of extraneous microorganisms. The results of studying the acidity of meat for several days characterized it as fresh and obtained from a healthy bird, as the decrease in the indicator met the requirements.

\section{Conclusion}

To produce "organic" poultry meat of Hubbard RedBro cross, increase its productivity, safety, improving the Biosafety and bio-value of poultry meat products, recommended growing cross at a cellular or floor content, depending on the possibility of farming, using mixed feeds. By controlling biosafety indicators into birds' diet in combination with a probiotic-enzyme supplement, Bacell at a dose of $0.2 \%$ of the feed weight.

\section{Acknowledgment}

The research was carried out with the financial support of the Kuban science Foundation in the framework of the scientific project № MFI-20.1/80.

\section{REFERENCES}

Alagawany M, Abd El-Hack ME and Farag MR, 2019. Nutritional strategies to produce organic and healthy poultry products. Sustainability of Agricultural Environment in Egypt. Part II: 339-356. https://doi.org/10.1007/698 2018 289.

Avarsky ND, Taran VV and Sokolova ZE, 2014. Organic products market: Current state and development prospects. Agricultural Economics of Russia 5: 29-37.

Belloir P, Méda B; Lambert W, Corrent E, Juin H, Lessire M and Tesseraud S, 2017. Reducing the CP content in broiler feeds: Impact on animal performance, meat quality and nitrogen utilization. Animal 11: 1881-1889. https://doi.org/ 10.1017/S1751731117000660

Boukili M, Filali FR, Aboulkacem A, and Sefiani M, 2019. Assessment of factors influencing the hygienic quality of retail beef meat in Meknes City, Morocco. International Journal of Veterinary Science 8: 43-48.
Chrystal PV, Moss AF, Khoddami A, Naranjo VD, Selle PH and Liu SY, 2020. Effects of reduced crude protein levels, dietary electrolyte balance and energy density on the performance of broiler chickens offered maize-based diets with evaluations of starch, protein and amino acid metabolism. Poultry Science 99: 1421-1431. https://doi.org/ 10.1016/j.psj.2019.10.060

Erwan E, 2018. Supplementation if caloric- and protein-restricted diets with l-leucine stimulates food intake and improves carcass characteristics in broiler chickens. International Journal of Poultry Science 17: 28-33.

Hilliar M, Huyen N, Girish, CK, Barekatain R, Wu S and Swick RA, 2019. Supplementing glycine, serine, and threonine in low protein diets for meat type chickens. Poultry Science 98: 6857-6865. https://doi.org/10.3382/ps/pez435

Hofmann P, Siegert W, Kenéz Á, Naranjo VDD and Rodehutscord M, 2019. Very low crude protein and varying glycine concentrations in the diet affect growth performance, characteristics of nitrogen excretion, and the blood metabolome of broiler chickens. Journal of Nutrition 149: 1122-1132. https://doi.org/10.1093/jn/nxz022.

Koshchaev AG, 2018. Engineering and development of probiotics for poultry industry. Asian Journal of Pharmaceutics 12: 1179-1185. http://dx.doi.org/10.22377/ ajp.v12i04.2907

Lemme A, Hiller P, Klahsen M, Taube V, Stegemann J and Simon I, 2019. Reduction of dietary protein in broiler diets not only reduces n-emissions but is also accompanied by several further benefits. Journal of Applied Poultry Research 28: 867-880. https://doi.org/10.3382/japr/pfz045

Luneva AV, Lysenko YA, Koshchaev AG, Nesterenko AA and Guzenko VI, 2019. Comprehensive biosafety assessment of additives based on live microorganisms. International Journal of Engineering and Advance Technology 9: 2477-2483.

Lysenko Y, Luneva A, Koshchaev A, Lifentsova M and Gorpinchenko E, 2019. Quality assessment of biological product of microbial origin. International Journal of Engineering and Advance Technology 9: 2484-2488.

Miska KB and Fetterer RH, 2019. Expression of amino acid and sugar transporters, aminopeptidase, and the di- and tripeptide transporter PepT1; differences between modern fast growing broilers and broilers not selected for rapid growth. Poultry Science 98: 2272-2280. https://doi.org/10.3382/ps/ pey583

Mottet A and Tempio G, 2017. Global poultry production: Current state and future outlook and challenges. World's Poultry Science Journal 73: 245-256.https://doi.org/10.1017/ $\underline{\mathrm{S} 0043933917000071}$

Nkosi DV, Bekker JL and Hoffman LC, 2020. Impact of communal cattle farming practices on meat safety in central bushbuckridge, South Africa. International Journal of Veterinary Science 9: 90-96.

Piskaeva AI, Sidorin YY and Prosekov AYU, 2017. Comparative analysis of the activity of silver nanoparticles against native microflora from poultry processing plants wastes. Nano Hybrids and Composites 13: 176-183.

Prosekov A, Milenteva I, Sukhikh S, Dyshlyuk L, Babich O, Mitrokhin P and Asyakina L, 2015. Optimization of conditions for biodegradation of poultry industry wastes by microbial consortium. Asian Journal of Microbiology, Biotechnology and Environmental Sciences 17: 515-519.

Skvortsova LN, Koshchaev AG and Shcherbatov VI, 2018. The use of probiotics for improving the biological potential of broiler chickens. International Journal of Pharmacology Research 10: 760. https://doi.org/10.31838/ijpr/2018.10.04.132

Yusfin Yu S, Leontiev LI and Doronina OD, 2009. Environmentally friendly production: content and basic requirements. Ecology and Industry of Russia 3: 23-27. 